\title{
ANALISIS KELUHAN RASA SAKIT YANG DIALAMI PEKERJA PADA UKM SEPATU KULIT DI KOTA DENGAN MENGGUNAKAN KUESIONER SNQ
}

\author{
Rosnani Ginting', Alfin Fauzi Malik ${ }^{2}$ \\ Departemen Teknik Industri ${ }^{1}$, Alumni Departemen Teknik Industri ${ }^{2}$ \\ Universitas Sumatera Utara (USU) \\ Jl. Almamater, Kampus USU Medan 20155 Indonesia \\ email: rosnani_usu@yahoo.co.id
}

\begin{abstract}
Abstrak.Usaha Kecil Menengah (UKM) merupakan sumber ekonomi potensial di masyarakat yang mampu menggerakkan roda ekonomi sampai pada tataran masyarakat bawah. Berbagai keunggulan yang ada di UKM terdapat juga hal-hal yang perlu ditingkatkan salah satunya adalah metode kerja operator. UKM Bersaudara Jaya dan UKM Pak Sepatu Pak Alex yang memproduksi sepatu kulit juga merupakan UKM yang perlu mendapatkan perbaikan pada sistem kerjanya. Standard Nordic Questionnaire (SNQ) merupakan alat yang dapat mengetahui bagian-bagian otot yang mengalami keluhan dengan tingkat keluhan mulai dari Tidak Sakit (TS), agak sakit (AS), Sakit (S) dan Sangat Sakit. Perbaikan diawali dengan mengidentifikasi keluhan operator melalui penyebaran kuisioner Standard Nordic Questionnaire (SNQ). Hasil dari identifikasi ini diketahui para operator mengalami keluhan Musculoskeletal Disorders (MSDs). Kondisi ini terjadi dikarenakan seringnya operator bekerja dengan postur kerja yang janggal, yaitu postur membungkuk, duduk dan jongkok. Postur kerja ini memicu timbulnya gangguan pada otot, kesemutan, pegal, dan sakit pada sendi sehingga meninbulkan keluhan-keluhan operator. Keadaan ini mengindikasikan bahwa aktivitas tersebut tergolong kedalam kategori berbahaya dan dapat menyebabkan risiko MSDs. Pembuatan sepatu kulit dilakukan secara manual mulai dari proses penggambaran pola, pemotongan kulit dan penyesepan, pengeleman dan penjahitan potongan kulit, pemasangan busa dan lapisan kain dalam, pemotongan bagian karet alas/texon, pemasangan kulit dengan karet alas, penggerindaan sol, pengeleman sol hingga menjadi sepatu. Melihat kondisi di UKM ini dilakukanlah penelitian untuk mengetahui keluhan yang dirasakan pekerja dan selanjutnya dilakukan analisis dan perbaikan aktivitas serta postur kerja. Hal ini sebagai upaya untuk mengurangi MSDs dan keluhan-keluhan yang dirasakan oleh operator selama bekerja.
\end{abstract}

Kata Kunci : UKM, Pembuatan Sepatu Kulit, Kuisioner Standard Nordic Questionnaire (SNQ)

\section{Pendahuluan}

Pekerjaan yang dilakukan secara manual dengan postur kerja yang tidak alamiah dapat menimbulkan keluhan seperti pegal, kesemutan, dan nyeri pada tulang. Kondisi seperti ini akan berakibat pada timbulnya penyakit akibat kerja yaitu penyakit otot rangka atau Musculoskeletal Disorders (MSDs). MSDs berpengaruh signifikan pada pekerja yang menyebabkan sakit, nyri, mati rasa, kesemutan, bengkak, kekakuan, gemetar, gangguan tidur dan rasa terbakar. Menurut OSHA, MSDs adalah cidera atau gangguan pada jaringan lunak (seperti otot, tendon, ligament, sendi, dan tulang rawan) dan sistem saraf dimana cidera atau gangguan ini dapat mempengaruhi hampir semua jaringan termasuk saraf dan sarung tendon (Laraswati, 2009). Selanjutnya Peter Vi (2002) dalam Pratiwi (2010) menjelaskan bahwa, terdapat beberapa faktor yang dapat menyebabkan terjadinya keluhan otot skeletal, yaitu: 1) Peregangan otot yang berlebihan, 2) Aktivitas berulang, 3) Postur kerja tidak alamiah, 4) Faktor penyebab skunder, diantaranya: tekanan, getaran, mikrolimat, dan 5) Penyebab kombinasi, diantaranya: umur, jenis kelamin, kebiasaan merokok, kesegaran jasmani, kekuatan fisik, ukuran tubuh (antropometri).

UKM Bersaudara Jaya dan UKM Pak Sepatu Pak Alex memiliki masalah pada pekerja sehingga menggunkan Body Map Kuisioner pada pekerja untuk melihat keluhan kelelahan pekerja pada fasilitas kerja pada proses produksi. Melihat kondisi di UKM ini dilakukanlah penelitian untuk mengetahui keluhan yang dirasakan pekerja dan selanjutnya dilakukan analisis dan perbaikan aktivitas serta postur kerja. Hal ini sebagai upaya untuk mengurangi MSDs dan keluhan-keluhan yang dirasakan oleh operator selama bekerja.

Rumusan masalah dalam penelitian ini adalah proses penggambaran pola, pemotongan kulit dan penyesepan, pengeleman dan penjahitan potongan kulit, pemasangan busa dan lapisan kain dalam, pemotongan bagian karet alas/texon, pemasangan kulit dengan karet alas, penggerindaan sol, 
pengeleman sol hingga menjadi sepatu yang dilakukan secara manual (tanpa alat bantu) dengan posisi kerja berdiri atau pun duduk yang membungkuk dan menjongkok serta dilakukan secara repetitif selama 8 jam kerja dapat mengakibatkan terjadinya risiko keluhan Musculosceletal Disorders (MSDs).

\section{Landasan Teori}

\subsection{Keluhan Musculoskeletal}

Keluhan musculoskeletal adalah keluhan pada bagian-bagian otot skeletal yang dirasakan oleh seseorang mulai dari keluhan sangat ringan sampai sangat sakit. Apabila otot menerima beban statis secara berulang dalam waktu yang lama, akan dapat menyebabkan keluhan berupa kerusakan pada sendi, ligamen dan tendon. Keluhan hingga kerusakan inilah yang biasanya diistilakan dengan Musculoskeletal disorsders (MSDs) atau cedera pada sistem muskuloskeletal. Apabila pekerjaan berulang tersebut dilakukan dengan cara yang nyaman, sehat dan sesuai dengan standar yang ergonomis, maka tidak akan menyebabkan gangguan muskuloskeletal dan semua pekerjaan akan berlangsung dengan efektif dan efisien. Secara garis besar keluhan otot yang terjadi dapat dikelompokkan menjadi dua yaitu:

1. Keluhan sementara (reversible), yaitu keluhan otot yang terjadi pada saat menerima beban statis, namun demikian keluhan tersebut akan hilang apabila pembebanan dihentikan.

2. Keluhan menetap (persistent), yaitu keluhan otot yang bersifat menetap. Walaupun pembebanan kerja telah dihentikan, namun rasa sakit pada otot masih terus berlanjut

Peter vi (2000) menjelaskan bahwa, terdapat banyak faktor yang dapat menyebabkan terjadi keluhan musculoskeletal sebagai berikut

1. Peregangan otot yang berlebihan

Peregangan otot yang berlebihan pada umumnya sering dikeluhakan oleh para pekerja dimana aktivitas kerjanya menuntut pengerahan tenaga yang besar seperti aktivitas mengangkat, menarik, mendorong dan menahan beban yang berat

2. Aktivitas berulang

Aktivitas berulang merupakan pekerjaan yang dilakukan secara terus menerus seperti pekerjaan mencangkul, membelah kayu besar, angkut dan sebagainya. Keluhan otot terjadi karena otot menerima tekanan akibat beban kerja secara terus menerus tanpa memperoleh kesempatan untuk relaksasi.
3. Sikap kerja tidak alamiah

Sikap kerja tidak alamiah adalah

sikap

kerja yang menyebabkan posisi bagian bagian tubuh bergerak menjauhi posisi alamiah, misalnya pergerakan tangan terangkat, punggung terlalu membungkuk, kepala terangkat dan sebagainya

4. Faktor penyebab sekunder

Faktor penyebab sekunder ini adalah berupa tekanan langsung dari jaringan otot yang lunak atau getaran dengan frekwensi tinggi yang menyebabkan kontraksi otot bertambah.

Pengukuran terhadap tekanan fisik ini cukup sulit karena melibatkan berbagai faktor subjektif seperti kinerja, motivasi, harapan dan toleransi kelelahan. Alat ukur yang digunakan dpat dilakukan dengan berbagai cara mulai metoda yang sederhana sampai menggunakan sistem komputer. Salah satu dari metode tersebut adalah melalui Standard Nordic Questionnaire

\subsection{Standard Nordic Questionnaire}

Standard Nordic Questionnaire (SNQ) merupakan alat yang dapat mengetahui bagian-bagian otot yang mengalami keluhan dengan tingkat keluhan mualai dari Tidak Sakit (TS), agak sakit (AS), Sakit (S) dan Sangat Sakit (SS). Dengan melihat dan menganalisis peta tubuh maka dapat diestimasi jenis dan tingkat keluhan otot skeletal yang dirasakan oleh pekerja. SNQ merupakan suatu instrumen untuk menilai segmen-segmen tubuh yang dirasakan operator (menurut persepsi operator), apakah sangat sakit, sakit, agak sakit, dan tidak sakit. Pekerjaan ini dilakukan secara manual dengan sikap kerja yang tidak alamiah serta dilakukan dalam waktu yang lama, yaitu selama 8 jam kerja.

\section{Proses Produksi Pembuatan Sepatu Kulit}

Produksi dilakukan dengan 2 jenis yaitu Make to Order dan Make to Stock. MTO dilakukan karena penerimaan pesanan dari beberapa langganan. MTS dilakukan jika ingin menjual ke konsumen secara langsung.

Beroperasi setiap hari Senin sampai Sabtu, pekerja mulai beraktivitas pada pukul 9 pagi hingga pukul 6 sore. Sistem kerja yang diterapkan ialah sistem borongan dimana gaji pegawai dibayarkan setiap minggu sesuai dengan pekerjaan yang telah diselesaikannya. Jenis aliran bahan yang ada ialah jenis garis lurus. Pekerja juga sudah memiliki pembagian tugas masing-masing. Pada dasarnya pekerja dibagi dalam 2 kelompok, yakni bagian 
atasan dan bagian bawahan. Bagian Atasan memiliki tugas untuk membuat bagian atas sepatu. Aktivitas yang dilakukan diantaranya ialah pengguntingan pola, pengeleman, penyesepan, dan penjahitan. Sedangkan bagian bawahan ialah pekerja yang bertugas menyatukan bagian atasan dengan tapak hingga menjadi sepatu kulit yang utuh. Selain itu ada juga bagian finishing bertugas memberikan warna pada sepatu.

Tahapan proses produksi sepatu kulit ini dapat dijelaskan sebagai berikut :

1. Penggambaran Pola

Pekerja menggambar pola di atas kulit dengan didasarkan pada model sepatu yang akan dbuat. Penggambaran dilakukan secara manual dengan pensil.

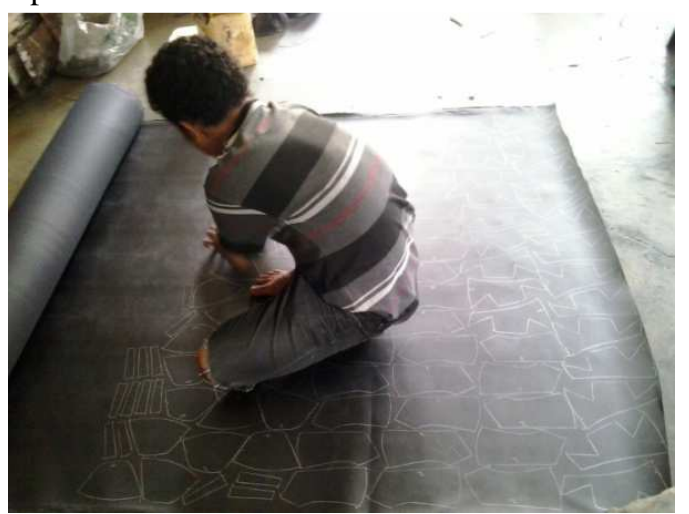

Gambar 1. Kegiatan Penggambaran Pola

2. Pemotongan Kulit dan Penyesepan

Setelah pola digambar, maka pekerja akan menggunting kulit berdasarkan pola-pola tersebut. Akan dilakukan penyesepan dengan mesin sesep pada hasil potongan agar mudah dalam pengeleman antar bagian.

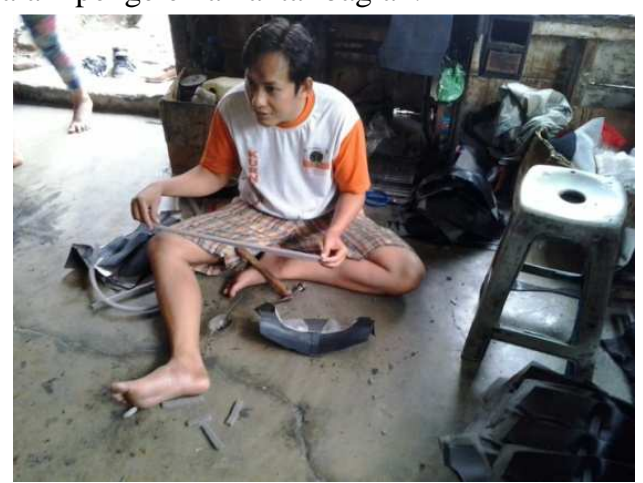

Gambar 2. Kegiatan Penyesepan
3. Pengeleman dan Penjahitan Potongan Kulit Potongan-potongan kulit dilem dan dijahit dengan mesin jahit sehingga membentuk bagian atasan dari sepatu.

4. Pemasangan Busa dan Lapisan Kain Dalam Busa dan lapisan kain dijahitkan ke bagian atasan sepatu sebelum dipindahkan dipindahkan kebagian pembuatan bagian bawahan

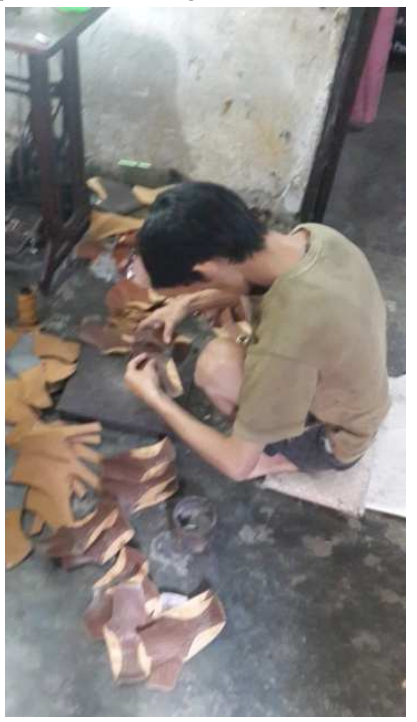

\section{Gambar 3. Kegiatan Pengeleman}

5. Pemotongan Bagian Karet Alas/Texon

Pekerja memotong karet sebagai alas sepatu dan menempelkannya pada mal.

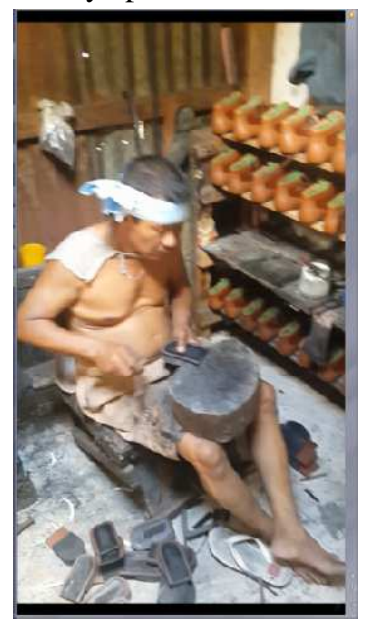

Gambar 4. Kegiatan Pemasangan Sol

6. Pemasangan Kulit dengan Karet Alas

Bagian Atasan dipasangkan pada mal dan disatukan dengan karet alas. 


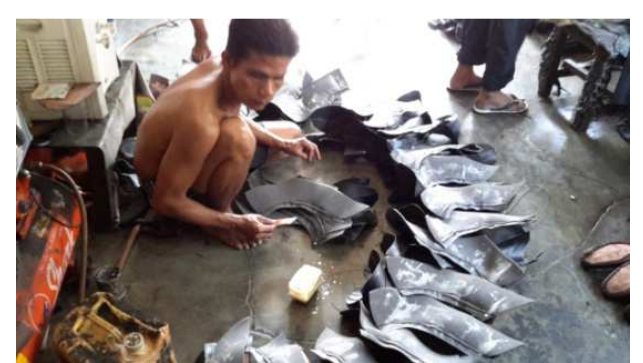

Gambar 5. Pemasangan Kulit dengan Karet Alas

7. Penggerindaan Sol

Sol digerinda agar halus setelah itu diberi cairan pembersih agar permukaannya lunak dan mampu menyerap lem

8. Pengeleman Sol hingga menjadi Sepatu

Sol kemudian dilem dengan bagian atasan sepatu. Setelah lem menempel dan mengeras, maka mal kaki dilepaskan dari sepatu.

9. Pengepresan Sepatu

Sepatu kemudian dipress untuk menghilangkan udara-udara yangmungkin ada didalam sepatu.

10. Finishing

Sepatu disemprotkan dengan bahan khusus untuk membuat permukaannya menjadi mengilat.

11. Pembuatan Merek

Tahap terakhir ialah pemasangan bagian merk pada permukaan atas dari alas dengan mesin stempel merek.

12. Pengepakan

Sepatu dikemas di dalam kotak

\section{METODE PELAKSANAAN}

Penelitian dilakukan dengan observasi di tempat kerja dengan sasaran yang meliputi pekerja dan fasilitas kerjanya. Tahap pertama pengambilan data adalah dengan menyebar kuesioner Standard Nordic Questionnaire (SNQ) untuk mengetahui pada bagian tubuh mana operator merasakan keluhan. Pada tahap ini akan dihitung tingkat resiko tertinggi pada operator.

\section{HASIL DAN PEMBAHASAN}

\subsubsection{Body Map Kuisioner}

Data ini didapatkan melalui penyebaran kuesioner SNQ. Data ini ditujukan untuk mengetahui bagian tubuh operator yang mengalami keluhan sewaktu melakukan aktivitasnya. Data hasil penyebaran Standard Nordic Questionnaire diberi penilaian atau pembobotan untuk masing-masing kategori sebagai berikut:

$\begin{array}{ll}\text { Tidak sakit } & \text { : bobot } 0 \\ \text { Agak sakit } & \text { : bobot } 1 \\ \text { Sakit } & \text { : bobot } 2 \\ \text { Sangat sakit } & \text { : bobot } 3\end{array}$

Kuisioner SNQ diberikan kepada 6 orang operator dan terdiri dari pertanyaan ke-0 hingga ke- 27

0 : Leher Bag. Atas

1 : Leher Bag. Bawah

2 : Bahu Kiri

3 : Bahu Kanan

4 : Lengan Atas Kiri

5 : Punggung

6 : Lengan Atas Kanan

7 : Pinggang

8 : Punggung

9: Pantat

10 : Siku Kiri

11 : Siku Kanan

12 : Lengan Bawah Kiri

13 : Lengan Bawah Kanan

14 : Pergelangan Tangan Kiri

15 : Pergelangan Tangan Kanan

16: Telapak Tangan Kiri

17 : Telapak Tangan Kanan

18 : Paha Kiri

19: Paha Kanan

20 : Lutut Kiri

21 : Lutut Kanan

22 : Betis Kiri

23 : Betis Kanan

24 : Pergelangan Kaki Kiri

25 : Pergelangan Kaki Kanan

26 : Telapak Kaki Kiri

27 : Telapak Kaki Kanan

\subsubsection{Perhitungan Persentase Keluhan Bagian Tubuh}

Setelah dilakukan rekapitulasi skor bobot SNQ pada pengumpulan data dimana diperoleh total skor bobot SNQ sebesar 114. Kemudian data skor rekapitulasi tersebut dirubah kedalam persentase. Untuk mendapatkan persentase tersebut dapat dicari dengan rumus :

$$
\% \text { Keluhan }=\frac{\text { Skor risiko bagian tubuh operator }}{\text { Jumlah skor risiko bagian tubuhoperator }} \times 100 \%
$$

Contoh: \% Skor Sakit di Leher Bagian Bawah $=\frac{11}{114}=$

$7,92 \%$ 
Tabel 1. Rekapitulasi Kuesioner SNQ

\begin{tabular}{|c|c|}
\hline Pertanyaan & Persentase \\
\hline 0 & $7,92 \%$ \\
\hline 1 & $3,96 \%$ \\
\hline 2 & $3,96 \%$ \\
\hline 3 & $4,95 \%$ \\
\hline 4 & $3,96 \%$ \\
\hline 5 & $4,95 \%$ \\
\hline 6 & $4,95 \%$ \\
\hline 7 & $8,91 \%$ \\
\hline 8 & $5,94 \%$ \\
\hline 9 & $2,97 \%$ \\
\hline 10 & $1,98 \%$ \\
\hline 11 & $1,98 \%$ \\
\hline 12 & $2,97 \%$ \\
\hline 13 & $2,97 \%$ \\
\hline 14 & $3,96 \%$ \\
\hline 15 & $3,96 \%$ \\
\hline 16 & $3,96 \%$ \\
\hline 17 & $3,96 \%$ \\
\hline 18 & $5,94 \%$ \\
\hline 19 & $5,94 \%$ \\
\hline 20 & $0,00 \%$ \\
\hline 21 & $0,00 \%$ \\
\hline 22 & $0,99 \%$ \\
\hline 23 & $0,99 \%$ \\
\hline 24 & $1,98 \%$ \\
\hline 25 & $1,98 \%$ \\
\hline 26 & $2 \%$ \\
\hline 27 & $2 \%$ \\
\hline
\end{tabular}

\section{Kesimpulan}

Setelah dilakukan perhitungan persentase keluhan secara keseluruhan, maka diperoleh bahwa rata-rata operator mengalami keluhan terbesar pada bagian tubuh antara lain :

1. Bagian pinggang $(8,91 \%)$

2. Bagian leher bagian atas $(7,92 \%)$

3. Bagian punggung $(5,94 \%)$

4. Bagian betis kiri $(5,94 \%)$

5. Bagian betis kanan $(5,94 \%)$

5. Bagian bahu kanan $(4,95 \%)$

6. Bagian punggung $(4,95 \%)$

7. Bagian lengan kanan atas $(4,95 \%)$

Dengan mengetahui presentasi keluhan yang sering dialami oleh pekerja pada UKM sepatu kulit Pak Alex dan Bersaudara Jaya, maka dapat diberikan sosialisasi kepada para pekerja untuk memperbaiki postur kerja bila perlu dilakukan pengadaan alat untuk membantu operator dalam bekerja.

\section{DAFTAR PUSTAKA}

Ginting, Rosnani. 2007. Sistem Produksi. Yogyakarta: Graha Ilmu

Sinulingga Sukaria, 2008. Pengantar Teknik Industri. Yogyakarta: Graha Ilmu

Sutalaksana, dkk. 1979. Teknik Tata Cara Kerja. Bandung: Penerbit Laboratorium Tata Cara Kerja dan Ergonomi Departemen Teknik Industri ITB.

Wignjosoebroto, Sritomo. 2005. Ergonomi, Studi Gerak dan Waktu. Surabaya: Guna Widya. 